\title{
RESEÑA: NORTE Y SUR. ELIZABETH GASKELL ${ }^{1}$
}

\author{
Blanca Puchol Vázquez ${ }^{2}$
}

\section{Elizabeth Gaskell. Norte y sur; María José Coperías (ed.); Elizabeth Power (trad.). Madrid: Cátedra, 2015. ISBN: 978-84-376-3360-2.}

Elizabeth Gaskell fue una reconocida novelista del panorama literario inglés de la época victoriana. Su fama ha fluctuado bastante desde sus días hasta el momento presente, llegando a pasar desapercibida en algunos momentos tanto para el público lector como para la crítica. A partir de 1960 parece resurgir el interés de la crítica por Gaskell y su obra y, si se atiende a las diversas ediciones de sus obras, puede decirse que su figura resurge también para el público lector. Es interesante mencionar el gran interés e importancia que tuvo en este resurgir del interés por esta novelista británica, la publicación en 1965 de sus cartas en una recopilación elaborada por John Chappel y Arthur Pollard, The Letters of Mrs. Gaskell, recopilación posteriormente ampliada y editada por el propio Chappel y, en esta ocasión, Alan Shelston, Further Letters of Mrs. Gaskell. Puede afirmarse que la aparición de las cartas resultó ser un punto de inflexión en la historia de la crítica existente en torno a esta novelista y con ello la importancia que empieza a recobrar tanto dentro del mundo académico como para el público general. Esta importancia de la publicación de las cartas es una idea que defienden muchos de los críticos posteriores a la aparición de las mismas como, por ejemplo Margaret Ganz, Angus Easson o Joanne Shattock.

\footnotetext{
${ }^{1}$ Fecha de recepción: 07/08/2016.

Fecha de aceptación: 09/08/2016.

${ }^{2}$ Colaboradora Honorifica, Departamento de Estudios Ingleses: Lingüística y Literatura, Universidad Cumplutense de Madrid; y Profesora de Lengua Inglesa, Universidad Internacional de la Rioja; $\square$ blanca.puchol@unir.net.
} 
En nuestro país, sin embargo, sigue siendo una autora bastante desconocida. Por ello es de gran interés la labor de María José Coperías quien a principios de 2015 publicó una nueva edición en Cátedra de una de las obras más conocidas de Gaskell, Norte y sur, de cuya traducción al español se ha hecho cargo Elizabeth Power. A través de esta traducción y sus notas a pie de página (esta edición cuenta con 189 notas repartidas entre la introducción y la novela en sí), Coperías y Power acercan el texto al lector español y lo familiarizan tanto con su autora como con la época en la que ésta vivió y escribió. A ello contribuye, además, la extensa introducción elaborada por María José Coperías, la cual ocupa las primeras noventa y seis páginas de la edición y en la que se acerca al lector a Elizabeth Gaskell, su vida y formación, su entorno y amistades, el momento histórico en el que vivió y el progreso de su labor literaria, elementos todos ellos importantes a la hora de entender su producción literaria así como algunos de los elementos presentes en la novela aquí estudiada. Si bien es verdad que todos los apartados que componen dicha introducción son adecuados e interesantes, en cuanto a contenido y extensión, quizás sería interesante hacer un estudio un poco más en profundidad de la evolución literaria de la novelista haciendo hincapié en los puntos en común que pueden encontrarse en todas sus obras. Por lo demás puede decirse que los datos biográficos que aquí se presentan son los estrictamente necesarios para comprender a Elizabeth Gaskell, su tiempo, su vida y su obra.

Gaskell escribió acerca de aquello que veía y conocía, por lo que sus novelas son un reflejo de su experiencia vital. Es interesante la división de opiniones que ha existido, desde su propio tiempo, en torno a si su producción literaria sufrió o se benefició de su ajetreada vida. Shirley Foster alude a la estrecha relación entre biografía y producción artística existente en el caso de la literatura de Gaskell:

The links between biography and artistic production are particularly important in considering the Works of Elizabeth Gaskell. She herself, unlike some of her female litrary contemporaries, successfully combined marriage, motherhood, engagement with local affairs, and an often hectic social and cultural life with constant creative activity. [...] (Foster 2002: 1) 
También menciona el hecho de que algunos amigos de la novelista se preguntaron cómo era capaz de combinar sus tareas domésticas y sociales con las artísticas. Otros, sin embargo, consideraron que en el caso de Gaskell la relación entre vida y arte fue productiva.

Otros muchos críticos, independientemente del momento histórico-crítico, defendieron también la idea de que Gaskell refleja en sus obras aquello que vivió y experimentó y, también, varios son los que mencionaron la influencia, para unos positiva y para otros negativa, que tuvo su ajetreado estilo de vida en sus escritos. Así, Chadwick defiende la idea de que Gaskell escribe mejor cuando lo hace acerca de aquello que conoce que cuando lo hace en torno a cuestiones de su propia invención, Bald alude al reflejo que hace Gaskell de acontecimientos cotidianos, lo cual acerca al lector a la realidad; Johnston comenta la utilización por parte la novelista de hechos que ocurrieron en el Mancherster de su época; Hopkins menciona en sus estudios el realismo con que Gaskell describe tanto su entorno como a sus personajes; y también en los estudios de Wright, Gérin y Angus Easson pueden encontrarse alusiones al uso que hace Gaskell de su propia experiencia a la hora de escribir.

Por ello la introducción elaborada para Cátedra por Coperías es de gran interés, ya que acerca al lector a la época en la que vivió Gaskell así como a su estilo de vida, gustos, familia, amistades, intereses, etc. Comienza dicha introducción con un breve resumen de los rasgos más destacables de la novelista, como su gran sociabilidad, la cual le llevó a relacionarse con un gran número de personas de diversa procedencia y condición social; interés por las escuelas dominicales, las clases para obreros y el trabajo social con los pobres de Manchester; preocupación por la situación de los obreros en las fábricas así como por la de las jóvenes prostitutas; persona dinámica y comprometida, independiente, optimista, espontánea, franca y divertida; esposa y madre dedicada a sus obligaciones familiares, aunque en ocasiones anhelara una mayor libertad personal y disponibilidad para poder escribir; mujer, en definitiva, "extraordinaria, aunque no única, para su época y su vida fue intensa y muy activa" (Coperías 2015: 9). Tras este breve resumen, Coperías expone y comenta los rasgos más característicos y destacables de la familia de Gaskell y cómo influyeron en la conformación de su persona; la educación y 
formación que recibió en su infancia y adolescencia; la procedencia y formación de William Gaskell, futuro marido de Elizabeth, sus gustos e intereses comunes así como sus diferencias de carácter y el hogar que ambos construyeron junto a sus hijas; todo lo cual da un idea de la experiencia vital de la escritora y ayuda a comprender su producción literaria.

A continuación Coperías pasa a exponer los rasgos más característicos de Gaskell como escritora de entre los que destaca su capacidad innata para narrar historias así como su personalidad ingeniosa e imaginativa. Destaca el hecho de que los relatos y narraciones cortas se adaptaran mejor a su forma de escribir lo cual, además, explicaría los problemas y ansiedades que le provocaron la elaboración y publicación de sus novelas, siendo su ajetreada vida, unido a las exigencias de las publicaciones periódicas, otro de los factores de estrés a la hora de escribir sus obras de mayor extensión. Ejemplo de ello puede encontrarse en una de sus cartas donde menciona que no ha escrito nada a causa de mareos y dolores de cabeza: “... I have not written one line of "Margaret” for three weeks for headaches and dizziness" (Chapple 1991: 294).

Además de sus rasgos principales como escritora Coperías hace un repaso a sus diversas publicaciones, desde los primeros relatos, publicados por William Howitt, hasta la última de sus novelas, Wives and Daughters, destacando los factores que le indujeron a la redacción de algunos de sus trabajos, los problemas de publicación a los que se enfrentó y la crítica surgida tras la aparición de algunas de estas novelas. También comenta la relación que Gaskell mantuvo con sus editores, relación tempestuosa en el caso de Dickens y de Chapman frente a un mayor entendimiento y amistad, no sin sus roces, con su último editor, George Smith. También alude a las amistades literarias de Gaskell con otras escritoras de la época como Charlotte Brontë, Harriet Martineau, Elizabeth Barret Browning o George Eliot.

A continuación procede Coperías a analizar la novela aquí editada, Norte y sur. Y comienza trazando las líneas generales de la situación de la Inglaterra Victoriana, situación que da comienzo a finales del siglo XVIII con el comienzo de la Revolución Industrial, la cual fue transformando la economía del país y, con ello, su geografía puesto 
que la gran expansión e importancia que fueron cobrando las ciudades industriales y sus fábricas provocaron un masiva migración del campo a las ciudades. Movimientos de población, revueltas para el cambio de las leyes económicas y políticas existentes, crecimiento de las ciudades, barrios pobres en los que se hacinaban los obreros, grandes diferencias entre pobres y ricos, revueltas sociales, huelgas, etc. son algunos de los rasgos que Coperías muestra y explica, dada su estrecha relación con la novela de Gaskell en la cual la autora trata las relaciones entre patrones y obreros. Lo hace utilizando el personaje de Margaret Hale, protagonista de la novela, y su experiencia para guiar al lector por una historia de desacuerdos, malentendidos, enfrentamientos, huelgas, aprendizaje y mutuo entendimiento final.

Margaret Hale, joven procedente de un pueblecito del sur de Inglaterra, y criada en Londres, se traslada a Milton (Manchester), ciudad que se convertirá en su nuevo hogar, junto a sus padres. La familia se traslada de su acogedor hogar en el campo a esta ciudad industrial tras el abandono del señor Hale, padre de Margaret, de su ministerio como pastor de la Iglesia de Inglaterra. Para Margaret todo en Milton es nuevo y extraño: sus gentes, las relaciones sociales entre sus habitantes, las fábricas y el humo de sus chimeneas... Y es precisamente a través de sus ojos como la autora va presentando los acontecimientos principales: el enfrentamiento y distinto parecer entre obreros $\mathrm{y}$ patronos, la huelga y sus consecuencias (tanto personales como económicas), el estado de pobreza de los obreros, la falta de comunicación y entendimiento entre clases... Margaret va aprendiendo y conociendo la situación, por un lado, de los obreros a través de su amistad con Bessy Higgins y su padre Nicholas, así como los ideales y situación de los empresarios a través de John Thornton, y termina convirtiéndose en un puente que trata de unir ambos mundos.

Alrededor del tema principal de la lucha de clases fluctúan otros temas y acontecimientos como son la tolerancia y convivencia de religiones (Margaret es anglicana, los Thornton y su padre disidentes, Bessy metodista y su padre Nicholas ateo, y Frederick, hermano de Margaret, se convierte al catolicismo por amor); las muertes de varios de los personajes principales; el riesgo que Frederick, exiliado del país por participar en un motín, corre para ver a su madre moribunda; el malentendido que se 
produce cuando Thornton ve a Margaret con su hermano (cuya existencia Thornton desconoce) paseando lejos de su casa y a horas muy tardías; la quiebra de Thornton como consecuencia de una huelga y cómo es finalmente rescatado por Margaret quien ha heredado una alta suma de dinero tras la muerte de su padrino, el señor Bell, son algunos de los acontecimientos que van tejiendo el trasfondo de la historia principal y que Coperías menciona en su estudio y comentario de la obra.

Con esta nueva edición, María José Coperías y Elizabeth Power acercan el texto al lector actual y le facilitan su lectura a través de la introducción, aquí comentada, y las notas a pie de página que pueden encontrarse a lo largo del texto, gracias a las cuales el lector de hoy puede conocer hechos concretos de la Inglaterra Victoriana que están reflejados, algunos de ellos específicamente mencionados, en la novela.

Esta es, pues, una edición muy interesante y recomendable tanto para su lectura como para su estudio.

\section{Referencias bibliográficas}

Bald, Marjory A. 1963. Women-Writers of the Nineteenth Century. New York: Russell and Russell. http://hdl.handle.net/2027/uc1.b4281060 [12 diciembre 2014].

Chappel, J.A.V.; Pollard, Arthur (ed.). 1997. The Letters of Mrs. Gaskell. Manchester: Mandolin.

Easson, Angus. 1979. Elizabeth Gaskell. London: Routledge and Kegan Paul Ltd.

Easson, Angus. 1991. Elizabeth Gaskell: The Critical Heritage: 1848-1910. London: Routledge.

Foster, Shirley. 2002. Elizabeth Gaskell. A Literary Life. Basingstoke: Palgrave Macmillan.

Ganz, Margaret. 1969. Elizabeth Gaskell: The Artist in Conflict. New York: Twayne Publishers, Inc.

Gaskell, Elizabeth. 2015. Norte y Sur / Elisabeth Gaskell (edición de María José Coperías; traducción de Elisabeth Power). Madrid: Cátedra.

Gérin, Winifred. 1976. Elizabeth Gaskell: a Biography. Oxford: Clarendon Press. 
Hopkins, A. B. 1931. "Liberalism in the Social Teachings of Mrs. Gaskell". Social Service Review, The University of Chicago Press 5 (No. 1): 57-73. http://www.jstor.org/stable/30009643?seq=1\#page_scan_tab_contents [26 septiembre 2014].

Hopkins, A. B. 1952. Elizabeth Gaskell. Her Life and Work. London: John Lehmann.

Johnston, Josephine. 1928. "The Sociological Significance of the Novels of Mrs. Gaskell." Social Forces, Oxford University Press 7 (No. 2): 224-227. http://www.jstor.org/stable/2570143 [26 septiembre 2014].

Shattock, Joanne (ed.). 2005. The Works of Elizabeth Gaskell. Vol. 1, Journalism, Early Fiction and Personal Writings. London: Pickering and Chatto,

Wright, Edgar. 1965. Mrs. Gaskell: The Basis for a Reassessment. London: Oxford University Press. 